\title{
A risk based maintenance (RBM) interval decision making model to support life extension of subsea oil and gas facilities
}

\author{
I. Animah, M. Shafiee \\ Cranfield University, College Road, Bedfordshire MK43 OAL, United Kingdom
}

\begin{abstract}
A substantial number of production facilities in the subsea oil and gas industry are approaching their anticipated service life and thus, require to undergo a life extension program. In effect, the volume of maintenance activities to be undertaken on facilities in the subsea fields is growing rapidly. The current inspection and maintenance decision-making approaches to support life extension of subsea oil and gas facilities are mainly based on subjective experience and judgement of inspectors and engineers which may be inconsistent, inaccurate and unreliable. Therefore, it is of great interest for asset managers to propose sound approaches for maintenance of subsea facilities operating beyond their original design life. In this study, a quantitative riskbased maintenance (RBM) interval decision-making model is presented to minimize cost as well as the overall risk associated with life extension. The model provides an effective tool for maintenance planning of subsea equipment during the extended phase of operation by considering the probability of failure and the consequences associated with failures of the equipment. The likelihood of failure is modelled using Weibull distribution due to its inherent flexibility, and the failure parameters are determined using physical equipment data by means of maximum likelihood estimation (MLE) method. On the other hand, the economic consequences of failure is calculated by considering asset loss, production loss, human health loss and maintenance cost. The proposed framework is applied to a case study involving a subsea flowline and the results are discussed and evaluated.
\end{abstract}

\section{INTRODUCTION}

The international oil and gas industry has witnessed considerable growth and technological innovations over the last decade. Nonetheless, a significant number of facilities in the subsea fields are approaching the end of their original design life. As the production from these fields is still economically viable, subsea suppliers have received a great number of requests from operators to assess the possibility of extending the service life of old facilities. Figure 1 represents the number of subsea wells operating in the world (blue number) along with their average age in years (red number). As shown, a total of 4672 subsea wells were operating in shallow waters amongst which, over 360 wells operated beyond their original design life.

The failure of subsea facilities can breakdown or reduce production during life extension phase of operation. This proves to be financially harmful to the operators. Furthermore, failure of subsea facilities may cause loss of containment, resulting in safety and environmental consequences. This would lead to possible implications on the company's finances and reputation.

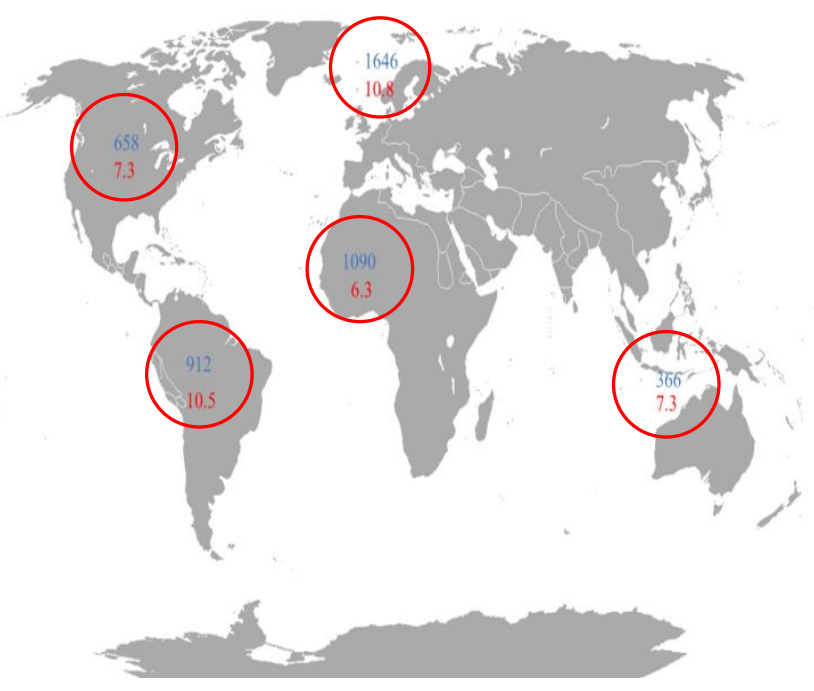

Figure 1. Number of producing subsea wells operating in shallow water of 70m and their averages age (Tveit et al., 2014). 
According to Strutt and Baker (2010), the cost of failure for a subsea facility is significant and will have adverse effects on the company's financial projections. To avoid expensive repair or replacement of facilities, there will be a need to develop an optimal maintenance strategy during the life extension period of operation without significantly increasing operational cost. The traditional inspection and maintenance decision-making approaches to support subsea equipment during the life extension phase of operation are based on subjective principles, accumulated operational experience and expert appraisal by inspectors and engineers, which often result in a little added value. Moreover, Tang et al. (2015) suggested that the equipment operating in offshore oil and gas industry are different from the equipment in other industries in terms of failure modes, failure distribution, maintenance cost, risk, reliability and safety requirements due to the extremely harsh operational and environmental conditions. Therefore, maintenance decision making models in other industries cannot overcome the maintenance challenges associated with subsea facilities, especially during the life extension period of operation.

Risk Based Maintenance (RBM) decision-making is gradually becoming an interesting and profitable alternative to traditional maintenance decision-making approaches. This technique has been widely applied in the offshore oil and gas industry. However, applications can also be found in power generation, transportation, petrochemical, chemical processing, mining, healthcare and other industries. During a vast literature survey on RBM methodologies and its application, Dey (2001) and Dey (2004) presented a cost-effective risk-based inspection and maintenance decision support system (DSS) for onshore pipelines. Fujiyama et al. (2004) developed RBIM methodology for inspection and maintenance of steam turbine plant. Khan et al. (2004) proposed an RBM methodology for inspection and maintenance planning based on aggregative risk analysis and multi-attribute decision-making (MADM). The proposed approach was applied to four case studies involving molecular sieve tank, hydroterater, autoclave and methanol storage drum. Krishnasamy et al. (2005) proposed an RBM methodology for selection of critical components, evaluation of risks and planning of maintenance and inspection tasks. The proposed methodology is illustrated through a power-generating unit in the Holyrood thermal power generation plant. Liu et al. (2011) adopted an RBM technology for petrochemical industry to support maintenance decision making of power station boiler super heater. Tan et al. (2011) utilized RBM methodology to evaluate and select suitable maintenance strategy for Fuijian oil refinery ISOMAX plant. Khan et al. (2012) described the basic steps involved in RBIM philosophy and applied it to a case study involving a power generating unit. Wang et al. (2012) developed an RBM strategy based on the failure mode and effects analysis (FMEA) to support continuous operation of catalytic reforming plant. Hameed and Khan (2014) proposed a risk-based shutdown inspection and maintenance interval modelling approach for chilling/liquefaction processing plants. The study determined the optimal maintenance interval based on an "as low as reasonably practicable (ALARP)" criterion.

Despite numerous scientific works being published on RBM methodology, there has been a limited effort to use this approach for optimization of maintenance intervals for subsea facilities. The failure of these facilities leads to higher operating cost, resulting in significant production loss and reduction in stakeholders' investment returns. Hence, a quantitative RBM interval decision-making methodology is proposed in this study which enables the stakeholders to determine the optimal maintenance interval for subsea facilities during life extension period of operation by considering the risk level. This approach is a cost-effective tool to minimize the overall financial risk associated with subsea facilities' failure, while complying with availability and safety requirements during the life extension phase of operation.

The rest of the paper is organized as follow. Section 2 proposes a new analytical framework for determining maintenance interval. A case study to test and validate the proposed framework is presented in Section 3 and the results are subsequently discussed in Section 4. Finally, the conclusions and future work directions are presented in Section 5.

\section{THE PROPOSED FRAMEWORK}

In this Section, a framework is proposed to integrate reliability analysis with safety, cost of maintenance and economic consequences of failure during life extension phase of operation for subsea facilities. The framework proposed to help determine optimal maintenance interval for subsea facilities during life extension phase of operation is shown in Figure 2. 


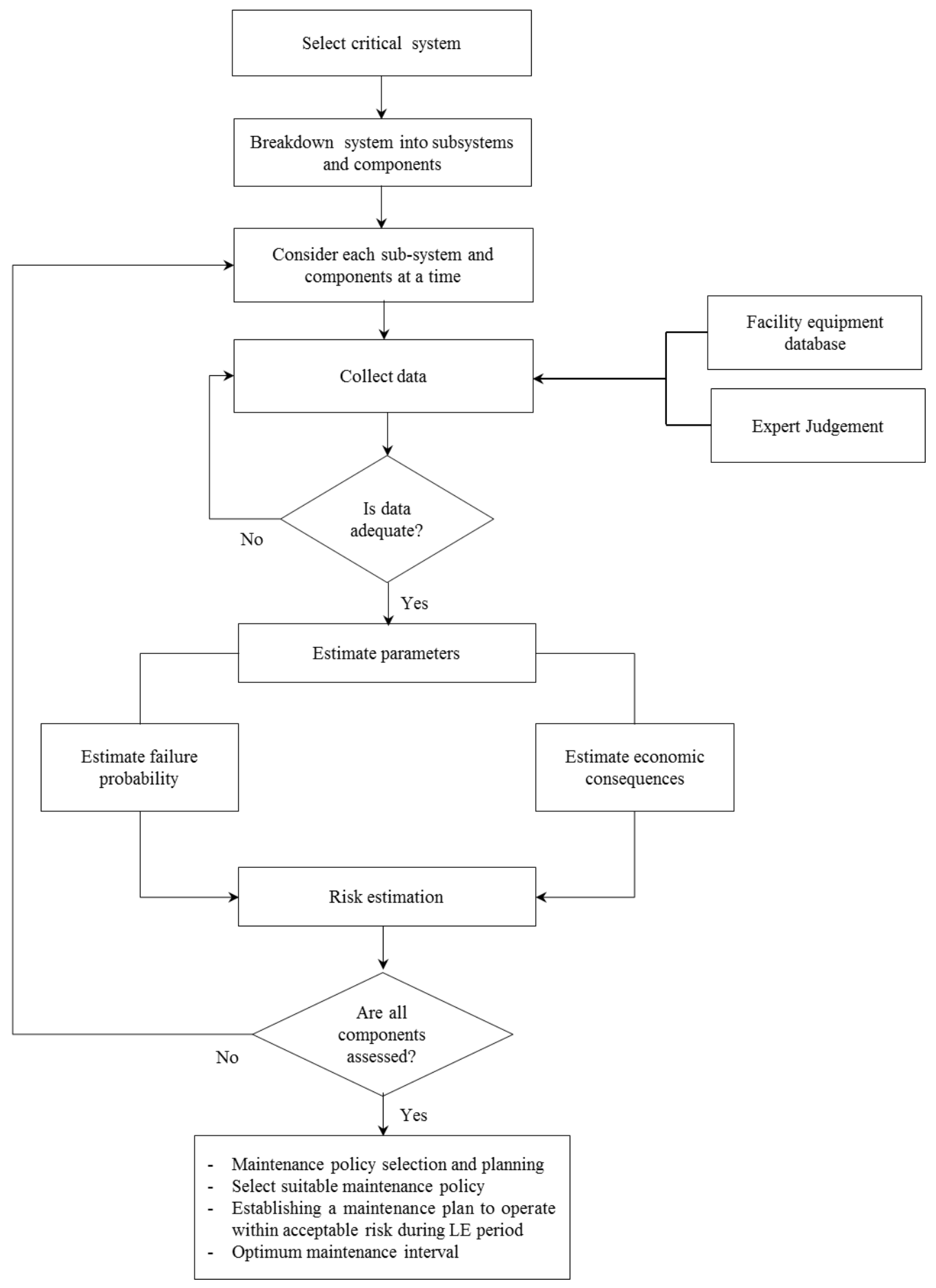

Figure 2. The framework for risk-based maintenance planning.

An essential aspect in the development of the above proposed framework was the strong collaboration among experienced researchers and industrial experts in undertaking life extension projects. These experts were selected from amongst regulators, safety technicians, subsea facility managers, and oil and gas consultants in the countries of Norway, UK and Gabon. The interactions with industrial experts aided in determining the current challenges of the offshore oil and gas industry concerning life extension of subsea facilities. The mode of interaction involved a face-toface semi-structured interview and an on-line survey. The key tasks of the proposed framework are discussed in the next sub-sections.

\subsection{Breakdown of system into components}

A majority of subsea facilities are complex mechanical systems, which means that focusing on the entire system for life extension will be complicated and time-consuming. Thus, decomposition of the system into manageable units would enable asset managers to focus on critical components of the system whose failure may cause the whole system to shut down. Rausand and Hoyland (2004) suggested that breaking down a whole system into manageable units help decision makers to focus on subsystem and components. The failure of these systems may significantly impact overall system availability, resulting in economic loss and marginal safety and environmental concerns.

\subsection{Data collection}


Quantitative safety, reliability and maintenance analysis of critical assets requires good quality and adequate failure data (Rausand and Øien, 1996). To determine the failure probability and perform consequence assessment, good quality data and specific engineering/scientific knowledge of the subsea facility considered for life extension is required. Failure data are obtained from laboratory testing, accelerated life testing (ALT), sensor information from monitoring systems, expert knowledge, component physical data and data handbooks such as OREDA, MIL-HDBK-189 and MIL-HDBK-217F. Additionally, design records, asset population density, age, product type, operating records (pressure and temperature) and cost information are examples of data required for subsea facilities life extension analysis.

\subsection{Estimation of parameters}

The calculation of failure probability of a subsea facility entails estimation of failure parameters. Failure parameters can be estimated using monitoring data, test data, and from operating experience of plant workers (Hameed and Khan, 2014). Depending on the available data, Monte Carlo simulation, maximum likelihood estimation (MLE) method or Bayesian reliability estimation method can be employed to estimate failure parameters. However, in the absence of good quality data, failure parameters can be obtained using expert judgement. Noortwijk et al. (1992) proposed a comprehensive approach of using an experts' judgement to obtain lifetime distribution for maintenance optimization.

In this study MLE method is used and the likelihood function is obtained from the expression in Eq. (1) (Balakrishnan and Kateri, 2008)

$$
f(t)=\frac{\beta}{\eta^{\beta}} t^{\beta-1} e^{-(t / \eta)^{\beta}} ; t>0, \beta, \eta>0 .
$$

The above distribution is commonly used in the field of risk and reliability engineering because of its simplicity. It can also easily mimic the shape of other distribution models.

\subsection{Estimate failure probability}

The failure of a system is defined as the inability of the system to perform its required function as per operating procedure in a defined environment. Rausand and Øien (1996) and Ebeling (1997) suggested that failure of a system is a fundamental concept of systems reliability. Systems reliability refers to the ability of a system to successfully perform its intended function in the given time. Therefore, the probability of failure of a system can be expressed using the reliability function below:

$$
\begin{aligned}
& R(t)+F(t)=1, \\
& F(t)=1-R(t) .
\end{aligned}
$$

According to Vaidya and Rausand (2011), the failure distribution for subsea equipment can be modelled as Gumbel, Weibull, log normal, inverse Gaussian and Birnbaum-Saunders distributions. However, Ghosh and Roy (2009) indicated that the Weibull distribution is more appropriate for failure analysis because it is a generalized failure distribution model. It can also easily mimic the behaviour of other failure distributions due to its inherent flexibility. For example, the parameter $\beta<1$ shows a decreasing failure rate and corresponds to the early life of the equipment. Whereas, the parameter $\beta=1$ shows that the equipment fails from random failure and $\beta>1$ shows an increasing failure rate with time. Also, compared to other distributions, Weibull distribution has the advantage of performing accurate failure analysis at the wear out stage of an asset life-cycle with a limited amount of data.

The reliability function for equipment following Weibull distribution is expressed in Ebeling (1997) as:

$$
\begin{aligned}
& R(t)=\exp \left[-\left(\frac{t}{\eta}\right)^{\beta}\right], \\
& \lambda(t)=\left(\frac{\beta}{\eta}\right)\left(\frac{t}{\eta}\right)^{\beta-1},
\end{aligned}
$$

where $R(t)$ represents the reliability of the system undergoing life extension and $\beta$ and $\eta$ are the shape and scale parameters.

\subsubsection{System configuration}

Numerous subsea equipment are made of complex configurations because of their intended function. Hence, to determine the appropriate reliability and availability, the estimating probability of failure of these facilities for life extension decision-making must consider the system's design and configuration. The system configurations are series, parallel or a combination of series/parallel.

\subsubsection{Series systems configuration}

The reliability of a series system configuration is expressed by Eq. (6).

$$
F_{s}(t)=1-\prod_{i=1}^{n} R_{i}(t),
$$

where $n$ represents the number of components in the series system.

\subsubsection{Parallel systems configuration}

The reliability of a parallel system configuration is expressed by Eq. (7).

$$
F_{p}(t)=\left[1-\prod_{k=1}^{m}\left(1-R_{k}(t)\right)\right] \text {, }
$$


where $m$ represents the number of components in the parallel system.

\subsubsection{Series/parallel configuration}

For the series/parallel system configurations, the failure probability is expressed in Eq. (8).

$$
F_{s p}(t)=[1-\overbrace{[\prod_{i=1}^{n} R_{i}(t) \times \overbrace{\left[1-\prod_{k=1}^{m}\left(1-R_{k}(t)\right)\right]}^{\text {series }} \text { Parallel }} .
$$

\subsection{Economic failure consequences}

Shafiee and Ayudiani (2015) categorized the economic consequences of failure in the energy industry into cost of failure, cost of inspection and cost of replacement. In this study, we adopt the same categorization for estimating economic consequences of the failure of subsea facilities during life extension phase of operation. Each of these is briefly explained below.

\subsubsection{Cost of failure}

The failure of any subsea facility requires immediate corrective action. This is because the failure of subsea equipment such as Christmas trees, manifold templates, flowlines and risers results in hydrocarbon release, which leads to a heavy fine from regulators and loss of reputation. The failure consequences of these facilities are not only limited to environmental damage but also lead to production loss, damage to nearby assets as well as health and safety issues. Therefore, the purpose of this stage of the framework is to quantify the potential consequences of failure to optimize maintenance interval. Subsequently, it also reduce the risk associated with life extension phase of operation of subsea facilities in the offshore oil and gas industry. The cost of failure is calculated in monetary terms considering asset damage loss cost (ADLC), human health loss cost (HHLC), production loss cost (PLC) and environmental damage loss cost (EDLC). Refer to Shafiee et al. (2016) for details on the estimation of these cost parameters readers.

\subsubsection{Cost of inspection}

The cost of inspection includes inspection cost and cost of technical support provided during inspection.

\subsubsection{Cost of replacement}

The replacement of subsea facilities due to failure requires preparation, logistical mobilisation and technical expertise. Hence, subsea replacement cost includes the cost of preparation (e.g. washing and purging), the cost of logistical mobilization (e.g. cost of spare parts, consumables, hiring of vessels for crew transport, etc.), the cost of technical expertise (e.g. cost of hiring experts for data analysis and maintenance planning) and cost of replacement. Thus, the total economic consequence of failure for the subsea facility is expressed as:
$\mathrm{ECF}=\sum_{i=1}^{n} \mathrm{CF}+\mathrm{COI}+\mathrm{CR}$

where $\mathrm{CF}$, COI and $\mathrm{CR}$ represent, respectively, cost of failure, cost of inspection, and cost of replacement and $n$ is the number of subsea equipment considered for life extension.

\subsection{Risk estimation}

API 581 (2000) and API 580 (2002) defined risk as product of probability failure and failure loss. Then, the cost of risk $C_{R}$ is expressed risk as:

$C_{R}=\int_{0}^{T} E C F(t) f(t) d t$,

where $C_{R}$ is considered as a function of time because in subsea operations, the cost of failure could depend on seasonal effects and time of day.

One uncompromising requirements for life extension decision making in the offshore oil and gas industry is to operate within an acceptable risk based on ALARP criterion. However, in practice the value of acceptable risk using the ALARP criterion is based on assumption of operators and regulators (Hameed and Khan, 2014), which in most cases does not help asset managers to determine the optimal maintenance interval for their assets. Therefore, applying the same criteria to determine the maintenance interval for subsea facilities during life extension phase of operation, where degradation increases with time will be very conservative. da Cunha (2016) suggested that more resources spent on preventive maintenance (PM) and inspection will result in less total failure cost in the long term. Therefore, to determine the optimum maintenance interval for subsea facility during life extension phase of operation taking into account risk level and PM is illustrated in Figure 3.

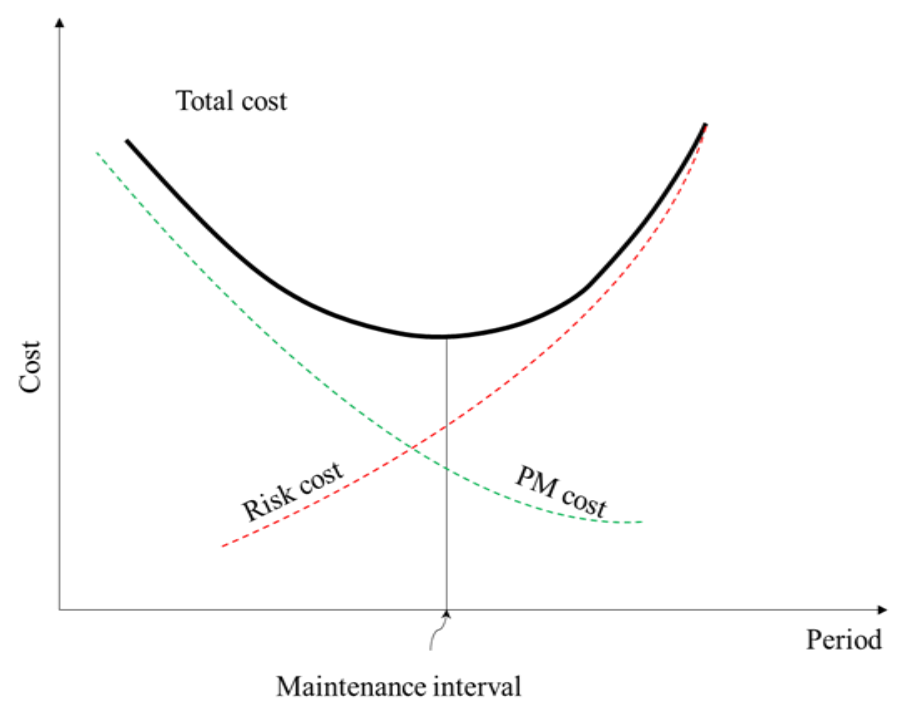

Figure 3. Risk cost vs PM cost 


\subsection{Maintenance interval optimization model}

As mentioned above, PM can lead to zero losses during life extension phase of operation. In this study, the procedure for optimum maintenance interval is presented as total maintenance cost optimization considering the risk cost. In context to Figure 4, when the age of the component lies between $(0, T)$, if a failure occurs, the failed component is replaced completely. However, the cost incurred is not the cost associated with replacement of failed component but the cost due to failure consequences. This is discussed in Section 2.5.

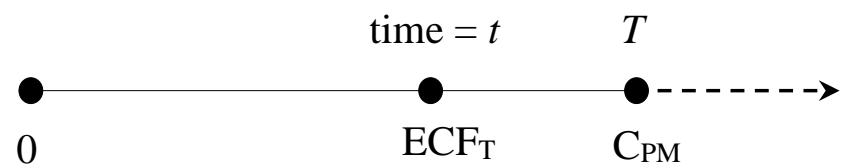

Figure 4. Determination of optimum maintenance interval

When the age of component reaches point $T$ preventive replacement is implemented. Thus the total maintenance cost $C(T)$, which is the objective function is expressed as:

$C(T)=C_{R}+C_{P M}$.

Referring to the cost function in Eq. (11), to operate at time $t$, we obtain a relative cost per unit time.

$C(T)=\frac{C_{R}+C_{P M}}{T}$,

where $C_{R}>C_{P M}$. Thus, Eq. (12) is written as:

$C(T)=\frac{\int_{0}^{T} E C F(t) f(t) d t+C_{P M} \int_{T}^{\infty} f(t) d t}{T}$.

We assumed that at time zero, $E C T=E C T_{0} \times e^{\lambda t}$. Hence, the optimum value is obtained by minimizing the objective function $C(T)$, i.e.,

$$
\left.\frac{d C(T)}{d T}\right|_{T=T^{*}}=0
$$

Eq. (13) is generalized for several maintenance intervals from the last maintenance intervention to the end of life service. Although, for the case study, we modelled the total maintenance cost as a special case. Then,

$$
C(T)=\frac{E C F[1-R(T)]+C_{P M}[R(T)]}{T} .
$$

\section{APPLICATION TO SUBSEA FLOWLINES}

In this section, the proposed methodology is applied to determine maintenance interval for an existing subsea flowline (see Figure 5). This asset has operated beyond the original design life, which was 30 years. The flowline considered in this study carries crude oil. It is a 16 " diameter $\times 12.5 \mathrm{~km}$, running from an existing subsea manifold to an FPSO, for processing and onward lifting by shuttle tankers. The existing reservoir is depleted and the company must decide the future use of the flowline. However, the operator has a new well, which could be economically explored if the existing flowline is fit for the purpose. The new well would tie a new subsea cooling spool back to the 30 -year old flowline of the existing manifold. The new well has High Pressure High Temperature (HPHT) characteristic with higher $\mathrm{CO}_{2}$ content compared to the existing well. This indicates that the existing flowline will be susceptible to sweet corrosion if the service life is extended. The function of the cooling spool is to reduce the temperature of the well product before entering the existing flowline. The integrity of the flowline was declared fit for extended operations after inspecting with an intelligent pig. However, operators must demonstrate that the existing pipeline can be maintained at intervals, because of operational characteristics of the new reservoir. This needs to be within acceptable risk limits to secure a licence for life extension.

The other factors considered in the application of methodology are:

- Standards: ISO/TS 12747 (2011) and NORSOK Y-002 (2010) were considered. However, after consulting company's internal staff, the ISO/TS 12747 (2011) standard, for technical specification of petroleum and natural gas - pipelines transportation system - recommended practice for pipeline life extension, was selected because NORSOK Y-002 (2010) is jurisdiction specific.

- Life extension period: The operator wanted to extend the service life of the flowline by 10 years which is the expected life span of the new reservoir.

- The operator's acceptable risk criterion (ALARP) is $\$ 17307 / \mathrm{h}$.

\subsection{RESULTS AND DISCUSSION}

In this section, the results obtained from the applied case is presented and discussed.

\subsection{Breakdown of system into subsystem and compo- nents}

The flowline system was broken into the subsea cooling spool, manifold template, tie-in spool and carbon steel flowline damage loop. Amongst the subsystems, the carbon steel flowline is selected for further analysis because of its criticality.

\subsection{Data collection}




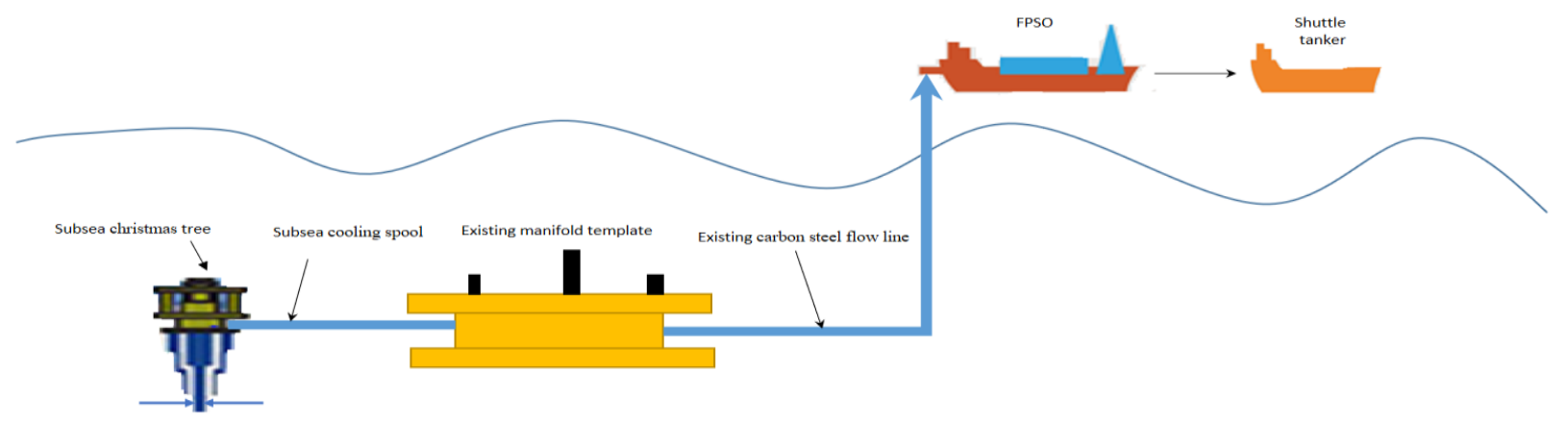

Figure 5. Schematic diagram of the flowline system

The data supporting the framework was obtained from historic records of companies as well as available literature (e.g. Shafiee et al. 2016) and handbooks (e.g. OREDA, 2009). In case data is unavailable, several surveys and interviews with pipeline construction firms and inspection companies are conducted.

\subsection{Failure probability, economic consequences of failure and PM cost}

The Weibull distribution parameters for carbon steel flowline, the estimated ECF and $\mathrm{C}_{\mathrm{PM}}$ are found in Table 1 .

Table 1. Weibull and cost parameters for flowline

\begin{tabular}{lllll}
\hline Components & \multicolumn{2}{c}{$\begin{array}{c}\text { Failure } \\
\text { parameters }\end{array}$} & ECF & $\mathrm{C}_{\mathrm{PM}}$ \\
\cline { 2 - 5 } & $\begin{array}{l}\text { Shape } \\
(\beta)\end{array}$ & $\begin{array}{l}\text { Scale } \\
(\eta, h r)\end{array}$ & $(\$) /$ Million & $(\$) /$ Million \\
& 2.0 & 350400 & 168.1 & 33.7 \\
\hline
\end{tabular}

The flowline's failure probability is calculated using the Weibull parameters in Table 1 and Eq. (6), defined in Section 2.4.1.1.

\subsection{Maintenance interval optimization}

From Figure 6, it can be deduced that the optimal maintenance interval is estimated to be $16,206 \mathrm{~h}$, where optimal risk cost is $\$ 9018 / \mathrm{h}$ or lower. Therefore, any maintenance frequency more than $16,206 \mathrm{~h}$ will be regarded as unacceptable. The failure rate of the flowline considers that the dent depth changes with time. Hence, the risk during life extension period of operation would also change with time. Furthermore, comparing the estimated risk cost to the ALARP based risk cost of operator, it is evident that this approach shows a significant saving to the operator. This can be invested in other projects.

\subsection{CONCLUSIONS}

The offshore oil and gas industry regards life extension as the best option amongst various end of life management strategies. This enables companies to achieve high availability and low cost of operation. The use of RBM methodology is the current trend for ensuring asset integrity in the offshore oil and gas industry. In this study a unique RBM model for estimating optimum maintenance interval for subsea facilities during life extension phase of operation is proposed. The proposed approach is different from existing RBM methodologies available in the literature. It considers both PM cost and total cost of failure to determine the optimal maintenance period, instead of assuming the ALARP criterion (Hameed and Khan, 2014).

A successful application of the proposed methodology requires estimation of the probability of failure and economic consequences of failure. The methodology has been applied to determine optimal maintenance interval for existing subsea facility operating in the life extension phase.

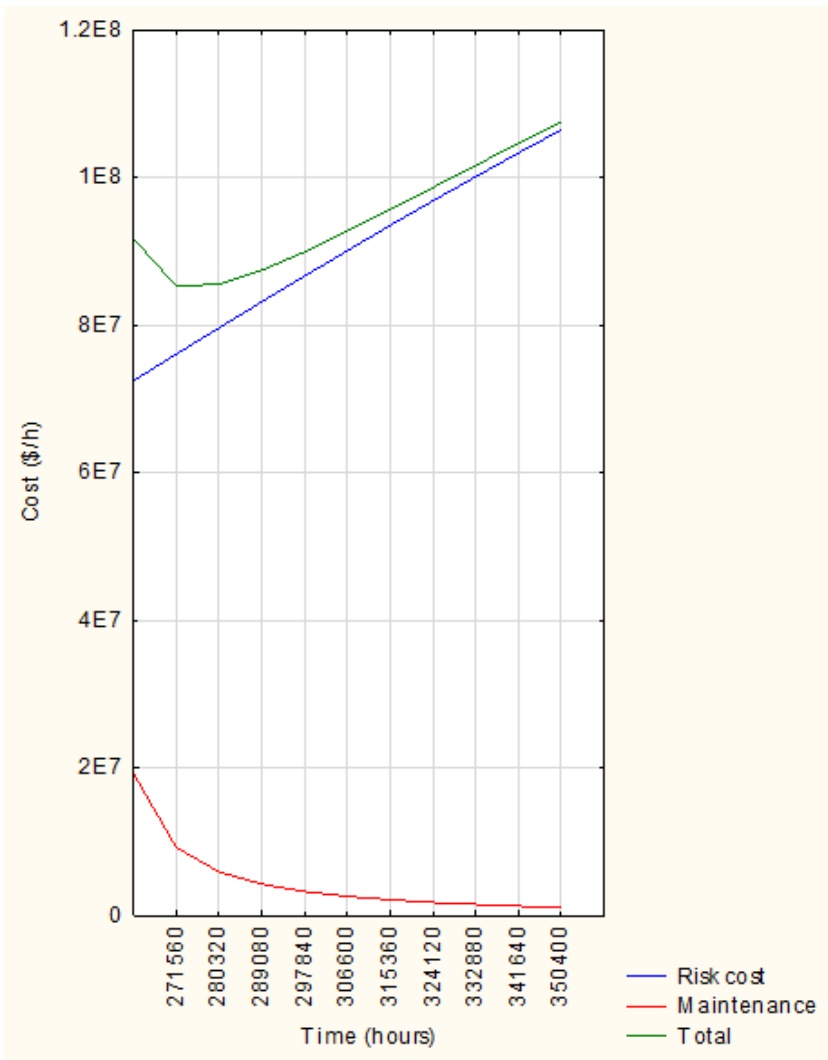

Figure 6. Optimal maintenance interval

The proposed methodology will help asset managers to optimize maintenance interval of subsea facilities during life extension period of operation. This 
will be done while considering the risk levels associated with production loss, safety and the environment. This approach is expected to provide cost-effective and better capital utilization during this phase.

Future work will apply the proposed model to process plant and other structural parts of the offshore oil and gas installation. It is recommended to the offshore oil and gas industry to provide platform, procedure and process for obtaining factual data to support life extension decision-making process. The effect of uncertainties on the optimal maintenance interval will be investigated into details in future applications.

\section{REFERENCES}

American Petroleum Institute. (2000). Risk-based inspection base resource document (1st ed.). API Publication 581.

American Petroleum Institute. (2002). Risk-based inspection (1st ed.). Recommended Practice 580.

Balakrishnan, N. and Kateri, M. (2008). On the maximum likelihood estimation of parameters of Weibull distribution based on complete and censored data. Statistics and Probability Letters, 78, 2971-2975.

da Cunha, S. B. (2016). A review of quantitative risk assessment of onshore pipelines. Journal of Loss Prevention in the Process Industries, 44, 282-298.

Dey, P.K. (2001). A risk-based model for inspection and maintenance of cross-country petroleum pipeline. Journal of Quality in Maintenance Engineering, 7(1), 25-43.

Dey, P.K. (2004). Decision support system for inspection and maintenance: a case study of oil pipelines. IEEE Transactions on Engineering Management, 51(1), 47-56.

Ebeling, C. (1997). An introduction to reliability and maintainability engineering. New York, N.Y, USA: McGraw Hill.

Fujiyama, K., Nagai, S., Akikuni, Y., Fujiwara, T., Furuya, K., Matsumoto, S. and Kawabata, T. (2004). Risk-based inspection and maintenance systems for steam turbines. International Journal of Pressure Vessels and Piping, 81, 825-835.

Ghosh, D. and Roy, S. (2009). Maintenance optimization using probabilistic cost-benefit analysis. Journal of Loss Prevention in the Process Industries, 22(4), 403-407.

Hameed, A. and Khan, F. (2014). A framework to estimate the risk-based shutdown interval for a processing plant. Journal of Loss Prevention in the Process Industries, 32(1), 18-29.

Khan, F., Haddara, M. and Khalifa, M. (2012). Risk-based inspection and maintenance (RBIM) of power plants. Springer Series in Reliability Engineering, 50, 249-279.

Khan, F. I., Sadiq, R. and Haddara, M. M. (2004). Risk-based inspection and maintenance (RBIM) of power plants: Multi-attribute decision-making with aggregative risk analysis. Process Safety and Environmental Protection, 86(2), 398-411.

Krishnasamy, L., Khan, F. and Haddara, M. (2005). Development of a risk-based maintenance (RBM) strategy for a power-generating plant. Journal of Loss Prevention in the Process Industries, 18(2), 69-81.

Liu, F. J., Kong, S. A, Ling, Z. W., Li, Q., Qian, Y. Q. and Zheng, M. L. (2011). Research and application of risk assessment methodology for power station boiler superheaters. Journal of Pressure Vessel Technology,
133(4), 1-10.

MIL-HDBK-189. (1981). Miltary Handbook Reliability Growth Management, Department of Defence, Washington, DC.

MIL-HDBK-217F. (1991). Miltary Handbook Reliability Prediction of Electronic Equipment, Department of Defence, Washington, DC.

Rausand, M. and Hoyland, A. (2004). System reliability theory. models, statistical methods and application (Vol. 2nd). BOOK, New York: wiley series in probability and mathematical statistic.

Rausand, M. and Øien, K. (1996). The basic concepts of failure analysis. Reliability Engineering \& System Safety, 53(1), 73-83.

Shafiee, M., Animah, I. and Simms, N. (2016). Development of a techno-economic framework for life extension decision making of safety critical installations. Journal of Loss Prevention in the Process Industries, 44, 299-310.

Shafiee, M. and Ayudiani, P. S. (2015). Development of a riskbased integrity model for offshore energy infrastructuresapplication to oil and gas pipelines. International Journal of Process Systems Engineering, 3(4), 211-231.

Strutt, J. E. and Baker, J. (2010). SS: offshore integrity: the lifecycle management of subsea facilities. In: Offshore Technology Conference, 3-6 May, Houston, Texas, USA, pp. 1 - 6.

Tan, Z., Li, J., Wu, Z., Zheng, J. and He, W. (2011). An evaluation of maintenance strategy using risk based inspection. Safety Science, 49(6), 852-860.

Tang, Y., Zou, Z., Jing, J., Zhang, Z. and Xie, C. (2015). A framework for making maintenance decisions for oil and gas drilling and production equipment. Journal of Natural Gas Science and Engineering, 26, 1050-1058.

Tveit, E., Sivertsen, H. and Hernaes, S. (2014). Experience from field life extension. In: Offshore Technology Conference, 05-08 May, Houston, Texas, pp. 1-8.

Vaidya, P. and Rausand, M. (2011). Remaining useful life, technical health, and life extension. Journal of Risk and Reliability, 225(2), 219-231.

van Noortwijk, J.M., Dekker, R., Cooke, R.M. and Mazzuchi, T.A. (1992). Expert judgment in maintenance optimization. IEEE Transactions on Reliability, 41(3), 427-432.

OREDA (2009) Offshore Reliability Data Handbook. SINTEF Energy, Norway.

Wang, Y., Cheng, G., Hu, H. and Wu, W. (2012). Development of a risk-based maintenance strategy using FMEA for a continuous catalytic reforming plant. Journal of Loss Prevention in the Process Industries, 25(6), 958-965. 